\title{
Human C-Tactile Afferents Are Tuned to the Temperature of a Skin-Stroking Caress
}

\author{
Rochelle Ackerley, ${ }^{1,2 *}$ Helena Backlund Wasling, ${ }^{1 *}$ Jaquette Liljencrantz, ${ }^{1,2}$ Håkan Olausson, ${ }^{2}$ Richard D. Johnson, ${ }^{1,3}$ \\ and Johan Wessberg ${ }^{1}$ \\ ${ }^{1}$ Department of Physiology, University of Gothenburg, Gothenburg 40530, Sweden, ${ }^{2}$ Department of Clinical Neurophysiology, Sahlgrenska University \\ Hospital, Gothenburg 41345, Sweden, and ${ }^{3}$ Department of Physiological Sciences, University of Florida College of Veterinary Medicine, Florida 32610-0144
}

\begin{abstract}
Human C-tactile (CT) afferents respond vigorously to gentle skin stroking and have gained attention for their importance in social touch. Pharmacogenetic activation of the mouse CT equivalent has positively reinforcing, anxiolytic effects, suggesting a role in grooming and affiliative behavior. We recorded from single CT axons in human participants, using the technique of microneurography, and stimulated a unit's receptive field using a novel, computer-controlled moving probe, which stroked the skin of the forearm over five velocities $(0.3$, $1,3,10$, and $\left.30 \mathrm{~cm} \mathrm{~s}^{-1}\right)$ at three temperatures $\left(\mathrm{cool}, 18^{\circ} \mathrm{C}\right.$; neutral, $32^{\circ} \mathrm{C}$; warm, $\left.42^{\circ} \mathrm{C}\right)$. We show that $\mathrm{CTs}$ are unique among mechanoreceptive afferents: they discharged preferentially to slowly moving stimuli at a neutral (typical skin) temperature, rather than at the cooler or warmer stimulus temperatures. In contrast, myelinated hair mechanoreceptive afferents proportionally increased their firing frequency with stroking velocity and showed no temperature modulation. Furthermore, the CT firing frequency correlated with hedonic ratings to the same mechano-thermal stimulus only at the neutral stimulus temperature, where the stimuli were felt as pleasant at higher firing rates. We conclude that CT afferents are tuned to respond to tactile stimuli with the specific characteristics of a gentle caress delivered at typical skin temperature. This provides a peripheral mechanism for signaling pleasant skin-to-skin contact in humans, which promotes interpersonal touch and affiliative behavior.
\end{abstract}

Key words: C-fiber; human; low-threshold mechanoreceptor; somatosensory; thermal; touch

\section{Introduction}

The unmyelinated touch afferent system was first described by Zotterman (1939), who reported responses from slowly conducting C-fiber low-threshold mechanoreceptors (CLTMs) in cats. A human equivalent was long-believed to have disappeared during evolutionary processes, until C-tactile (CT) afferents were found using the technique of microneurography (Nordin, 1990; Vallbo et al., 1993). The properties of CT afferents include maximal firing to slow-velocity stroking at low forces, small receptive fields with sensitive hot spots, and a slow conduction velocity relating to the unmyelinated axon (Vallbo et al., 1993, 1999; Wessberg et al., 2003; Löken et al., 2009). Brain imaging studies have shown that the posterior insular cortex is the primary cortical target area for CT afferents (Olausson et al., 2002;

\footnotetext{
Received July 4, 2013; revised Dec. 18, 2013; accepted Jan. 14, 2014.

Author contributions: R.A., H.B.W., J.L., H.O., R.D.J., and J.W. designed research; R.A., H.B.W., J.L., R.D.J., and J.W. performed research; R.A., H.B.W., and J.W. analyzed data; R.A., H.B.W., J.L., H.O., R.D.J., and J.W. wrote the paper.

This work was supported by the Swedish Research Council (Grant 2010-2607 to H.0. and Grant 62X-3548 to J.W.), Sahlgrenska University Hospital (Grant 144661 to H.0. and Grant 3161 to J.W.), and the Wenner-Gren Foundation (R.D.J., H.O.). We thank Profs. Åke Vallbo and Francis McGlone for helpful comments on this manuscript and Karin Göthner, Staffan Berg, and Dan Magnusson for excellent technical assistance.

${ }^{*}$ R.A. and H.B.W. contributed equally to this work.

The authors declare no competing financial interests.

This article is freely available online through the J Neurosci Author Open Choice option.

Correspondence should be addressed to Rochelle Ackerley, Department of Physiology, University of Gothenburg, Box 432, Gothenburg 40530, Sweden. E-mail: Rochelle@physiol.gu.se.

DOI:10.1523/JNEUROSCI.2847-13.2014

Copyright $\odot 2014$ the authors $\quad 0270-6474 / 14 / 332879-05 \$ 15.00 / 0$
}

Björnsdotter et al., 2009; Morrison et al., 2011), and their firing frequency correlates significantly with psychophysical ratings of tactile pleasantness (Löken et al., 2009).

CTs and CLTMs are found exclusively in hairy skin and have similar properties (Iggo, 1960; Bessou et al., 1971; Iggo and Kornhuber, 1977; Nordin, 1990; Vallbo et al., 1993, 1999; Wessberg et al., 2003; Liu et al., 2007; Löken et al., 2009; Li et al., 2011; Lou et al., 2013; Vrontou et al., 2013). In mouse genetic visualization studies, CLTMs have been found to express the vesicular glutamate transporter VGLUT3 (Seal et al., 2009; Li et al., 2011; Lou et al., 2013) and tyrosine hydroxylase (Li et al., 2011; Lou et al., 2013). Other studies show that another type of CLTM expresses the Mas-related G-protein-coupled receptor B4 (Liu et al., 2007; Vrontou et al., 2013) and that its pharmacogenetic activation is positively reinforcing (Vrontou et al., 2013).

Thus, both the human psychophysical and animal genetic studies show that CT activation is associated with hedonic effects, suggesting an important role for CTs in social touch (Olausson et al., 2010). Here we ask whether the complex tactile and temperature components that characterize a gentle skin-to-skin caress are encoded in the periphery by $\mathrm{CT}$ afferents. Three concurrent hypotheses were tested in humans using electrophysiological and psychophysical responses to combined mechano-thermal skin-stroking stimuli: (1) CT afferents respond preferentially to tactile and thermal stimulus components that resemble a human caress; (2) myelinated afferent firing is modulated differently to the same stimuli; and (3) the perception of pleasantness of the stimuli relates best to CT activity. 


\section{Materials and Methods}

The experimental procedures were approved by the University of Gothenburg ethics committee and performed in accordance with the Declaration of Helsinki. Written informed consent was gained, and participants were paid for their time. The subjects were well adjusted to the room temperature (kept constant at $23^{\circ} \mathrm{C}$ ) before the experiment started. Axonal recordings were made from the left antebrachial cutaneous nerve in 20 healthy human participants (age, $27 \pm 9$ years; mean and SD; seven males). Because of the intricacy of the technique, such as finding units in accessible locations, data from 18 participants were included in additional analyses. Psychophysical data were obtained in 30 different participants (age, $24 \pm 4$ years; mean and SD; 15 males). All participants were seated comfortably with their left arm immobilized using a vacuum airbag.

Using the in vivo electrophysiological technique of microneurography (Vallbo et al., 2004), single-unit axonal recordings were sought from A- and C-fiber mechanoreceptive afferents in the forearm through a high-impedance, tungsten recording electrode (FHC). The experimenter stroked the participant's arm gently to locate single units. Thus, the sample was biased toward low-threshold mechanoreceptive afferents. Units were classified as CTs when their spike configuration showed a major deflection in the negative direction, as expected for extracellular recordings from unmyelinated axons (myelinated units showed a major positive spike deflection), long latency responses to mechanical stimulation, and monofilament force thresholds of $\leq 2.5 \mathrm{mN}$ (Vallbo et al., 1993, 1999; Wessberg et al., 2003). The conduction velocity of CT units was estimated using a hand-held, blunt strain gauge device; responses were recorded to short mechanical taps to the center of the unit's receptive field, and the conduction velocity was calculated using the distance from this spot to the recording electrode (Vallbo et al., 1999). Myelinated A-fiber mechanoreceptive afferents were subclassified as slowly adapting type 1 (SA1) [or type 2 (SA2)] or rapidly adapting Pacinian, hair or field units according to their specific response and receptive field characteristic (Vallbo et al., 1995). Single units were identified on-line by the spike detection algorithms of the data acquisition system (SC/ZOOM; Department of Physiology, Umeå University, Umeå, Sweden), sampled at 12.8 $\mathrm{kHz}$, bandpass filtered $(0.2-4 \mathrm{kHz})$, and stored, using the SC/ZOOM system.

A rotary stimulator (Dancer Design; Fig. $1 A$ ) was used to move a mechano-thermal probe (contact surface, $\sim 5 \mathrm{~cm}^{2}$ ) across the center of a unit's receptive field. The size of this probe was sufficient to stimulate the full receptive field of a CT unit, which is $1-35 \mathrm{~mm}^{2}$ (Wessberg et al., 2003). Two variables were changed: the stroking velocity and the temperature of the stimulus probe. The contact surface of the probe was a rounded, smooth metallic plate, warmed and cooled with a customdesigned thermode consisting of probe-mounted Peltier elements (Melcor CP Series thermoelectric module) interfaced to Melcor PR-59 programmable control modules and thermocouples $\left(0.05^{\circ} \mathrm{C}\right.$ resolution). The probe was attached to an arm and central axle, which delivered different velocities of stroking $\left(0.3,1,3,10\right.$, or $\left.30 \mathrm{~cm} \mathrm{~s}^{-1}\right)$. This robotic stimulator provided high-precision computer control over the velocities and temperatures at a calibrated normal force $(0.4 \mathrm{~N})$. For each unit, three non-noxious temperatures were tested at all velocities: $\operatorname{cool}\left(18^{\circ} \mathrm{C}\right)$, neutral $\left(32^{\circ} \mathrm{C}\right.$; typical human arm skin temperature; Arens and Zhang, 2006), and warm $\left(42^{\circ} \mathrm{C}\right)$. The temperatures were presented in a pseudorandomized block design, where three repeats of each velocity were given in a randomized order in each temperature block. There was an interstimulus interval of $30 \mathrm{~s}$ to allow for recovery of the CT afferent response that can show fatigue in repeated stimulation (Zotterman, 1939; Iggo, 1960; Bessou et al., 1971; Hahn, 1971; Iggo and Kornhuber, 1977; Nordin, 1990; Vallbo et al., 1999). The paradigm took $\sim 40 \mathrm{~min}$; it was possible to record from the same unit during the whole paradigm, although some fluctuations and occasional drift in the recordings were seen. To ensure that there was no overall effect of the repetitive thermal stimulation on skin temperature, we measured skin temperature during the mechano-thermal stroking paradigm in six different participants (age, $40 \pm 12$ years; mean and SD; two males). We used an infrared thermometer (UT300B; UNI-T) to measure the skin temperature at the central
A

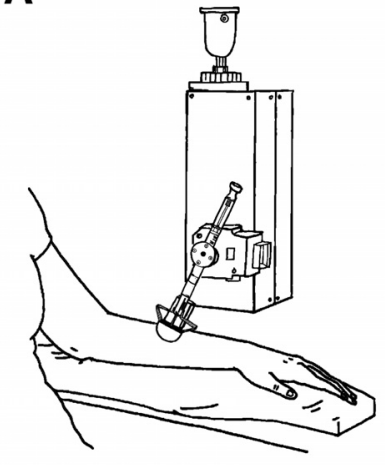

B

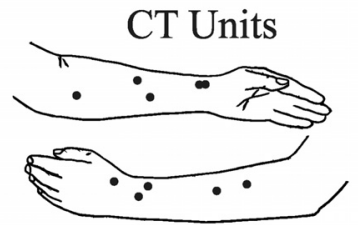

C

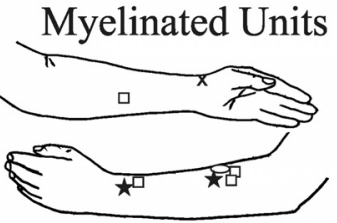

$\circ$ Field $\square$ Hair $\star$ SA $1 \times$ SA2

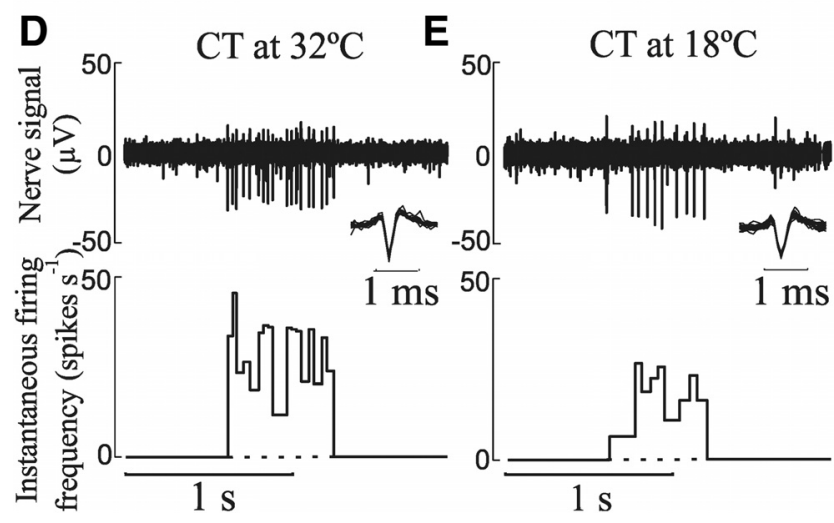

Figure 1. Experimental setup, locations of units, and examples of CT responses. A, Schematic of the setup with the rotary mechano-thermal stimulator positioned over the participant's arm. $\boldsymbol{B}, \boldsymbol{C}$, Receptive field locations of maximal responses from all the $C$ T units $(\boldsymbol{B})$ and myelinated units $(\boldsymbol{C})$ stimulated in the mechano-thermal experiment. $\boldsymbol{D}, \boldsymbol{E}$, Examples of raw spike traces and firing-frequency histograms from an individual CT unit in response to a stroking velocity of $3 \mathrm{~cm}$ $S^{-1}$ at the neutral $\left(32^{\circ} \boldsymbol{C} ; \boldsymbol{D}\right)$ and $\operatorname{cool}\left(18^{\circ} \boldsymbol{C} ; \boldsymbol{E}\right)$ temperatures.

point of skin stroking, directly before each stroke. The average prestimulus skin temperature was gained per stroking velocity block, and these were compared over time per temperature, where no significant changes were found (one-way ANOVA, all $p>0.1$ ). The average change in temperature from the beginning to the end of the block was $-0.6 \pm 0.3^{\circ} \mathrm{C}$ SEM for the cool block, $0.8 \pm 0.2^{\circ} \mathrm{C}$ SEM for the neutral block, and $1.0 \pm$ $0.2^{\circ} \mathrm{C}$ SEM for the warm block.

Psychophysical data were collected in a separate session, where the mechano-thermal stroking was delivered to the middle of the left forearm. The stimuli were presented in the same manner as in the mechanothermal paradigm, although instead of recording nerve responses, the participants rated each mechano-thermal stimulus on a visual analog scale (anchors "unpleasant" and "pleasant"; output range, -10 to +10 ). The subjects wore goggles, which shielded their view of the stimulus, and ear plugs.

The microneurography recordings were preprocessed to verify the single-unit nature of all units with an off-line pattern-matching algorithm, and the recorded nerve spikes were inspected in an expanded timescale using software implemented in MATLAB (Mathworks). Single spikes were time stamped, and the onset and offset of the probe movement were time-marked. Descriptive statistics were gained about the mean firing frequency of individual units, and stroking velocity was transformed to $\log _{10}$ values. Statistical comparisons were made using SPSS (version 18; IBM), and significances were sought below the $p<0.05$ level ( $p$ values are given for significance to three decimal places). Regressions testing linear and quadratic models were used to investigate curve fitting of the data from individual units/participants, and at the group level, for the stroking velocities, over each temperature. Multilevel mixed-model analyses were conducted to uncover statistically significant main effects of the stroking velocity and temperature, using maximum 

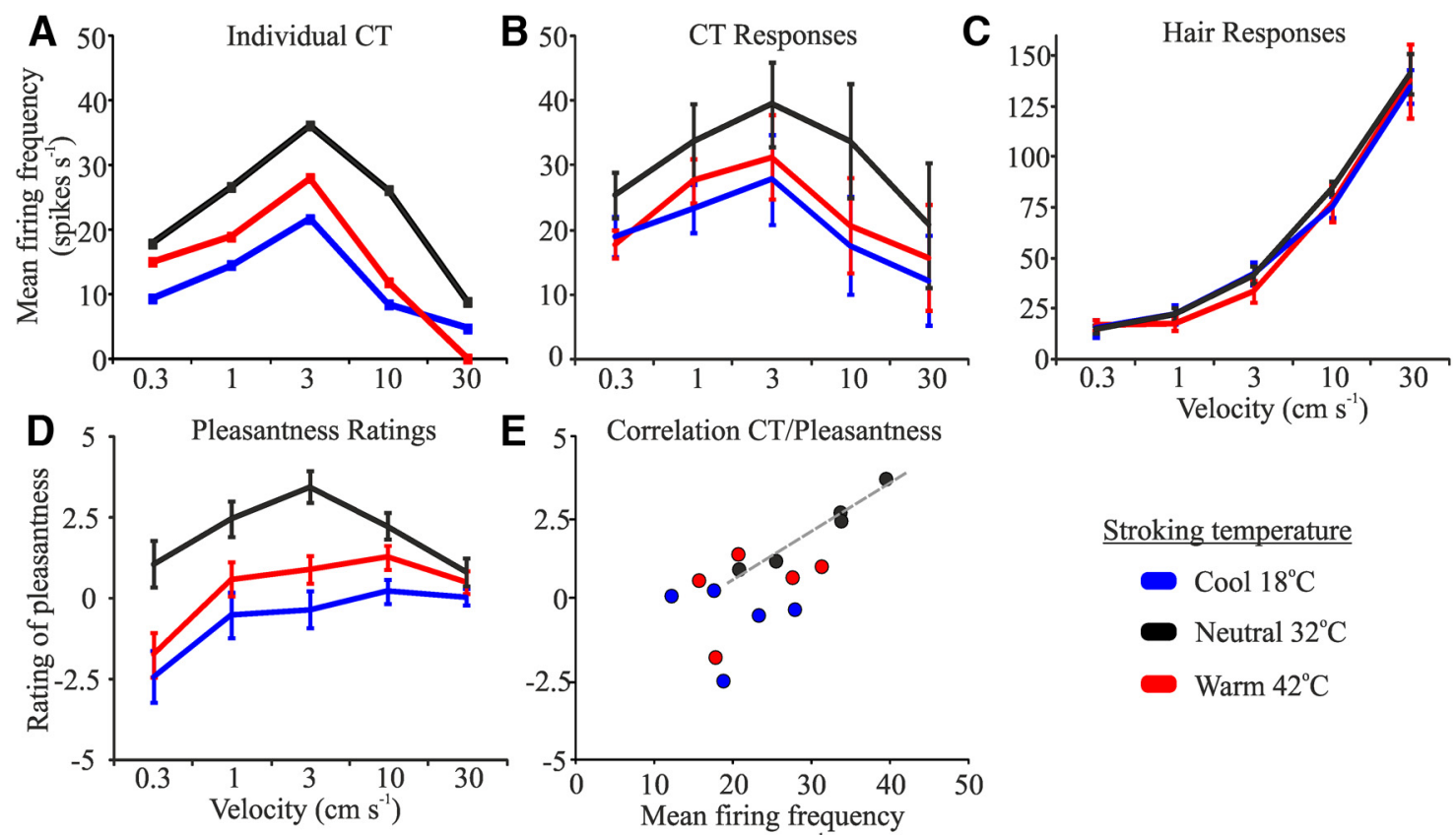

$\left(\right.$ spikes $\mathrm{s}^{-1}$ )

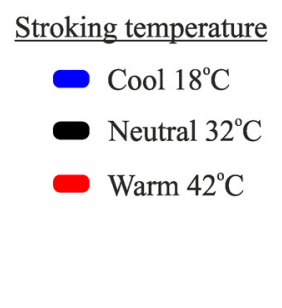

Figure 2. Neural firing and pleasantness ratings at different velocities and temperatures. $\boldsymbol{A}-\boldsymbol{D}$, Mean firing frequency of an individual $C T$ unit's response $(\boldsymbol{A})$, all $C T(\boldsymbol{B})$ and all hair $(\boldsymbol{C})$ units, and pleasantness ratings $(\boldsymbol{D})$ to the five stroking velocities and three temperatures. For $C T$ responses and pleasantness ratings, stroking at $3 \mathrm{~cm} \mathrm{~s}^{-1}$ at a neutral temperature produced the highest responses. All measures were affected by the stroking velocity, but only the CT firing frequency and pleasantness ratings showed an effect to temperature, where neutral produced the highest responses. $E$, CT firing frequency and pleasantness ratings correlated significantly, but only at the neutral temperature (regression line). Error bars indicate \pm SEM.

likelihood estimation and a random intercepts model; differences between the levels of each variable were compared using least significant difference tests. The firing-frequency data for CTs were compared with the mean pleasantness ratings, for each temperature, using Pearson's correlation two-tailed tests.

\section{Results}

Data were gained from 20 CT units, and their mean conduction velocity was $0.76 \mathrm{~m} \mathrm{~s}^{-1}$ ( \pm 0.06 SEM; range, $0.30-1.19 \mathrm{~m} \mathrm{~s}^{-1}$ ). The CT units were activated vigorously when the experimenter stroked the receptive field with slow, gentle movements; however, they did not respond to air puffs, which activated hair afferents. Eight CT units were tested using the moving mechano-thermal probe (Fig. 1). Other CT units were partially tested, but because of the highly technical and difficult recording environment, insufficient numbers of data points were gained, although these units showed the same trends as the group data. The CT units showed sensitivity to stroking velocity and temperature; their maximal mean firing frequency occurred at the stroking velocity of $3 \mathrm{~cm} \mathrm{~s}^{-1}$ and temperature of $32^{\circ} \mathrm{C}$ (Fig. $2 A, B$ ). Regression analyses were used to explore the relationship between CT firing frequency and stroking velocity, per temperature. Separate regressions were conducted per temperature, both for individual units and on a group level. All of the individual CT units were fit better by negative quadratic, rather than linear, regressions, and this was also true on a group level. For the neutral temperature, a significant inverted U-shaped, negative quadratic regression $\left(R^{2}=0.10\right.$, $\left.F_{(2,193)}=10.18, p<0.001\right)$ best fit the CT firing frequency to stroking velocity, where slower and faster velocities gave lower firing frequencies, compared with $3 \mathrm{~cm} \mathrm{~s}^{-1}$ (Fig. 2B). We also found similar significant negative quadratic fits for the cool $\left(R^{2}=0.08, F_{(2,229)}=10.06, p<0.001\right)$ and warm $\left(R^{2}=0.10\right.$, $\left.F_{(2,108)}=5.71, p=0.004\right)$ temperatures (Fig. $2 B$ ).

To uncover differences between the stroking stimuli, multilevel statistics were conducted on the CT firing-frequency data,
Table 1. CT firing frequency showed significant effects from changing the temperature of the moving probe

\begin{tabular}{|c|c|c|c|c|}
\hline \multirow[b]{2}{*}{$\begin{array}{l}\text { Velocity } \\
\left(\mathrm{cm} \mathrm{s}^{-1}\right)\end{array}$} & \multicolumn{4}{|c|}{ Significant differences in CT afferent firing frequency } \\
\hline & Main effect & $\begin{array}{l}\text { Neutral } \\
\text { versus cool }\end{array}$ & $\begin{array}{l}\text { Neutral } \\
\text { versus warm }\end{array}$ & $\begin{array}{l}\text { Warm } \\
\text { versus cool }\end{array}$ \\
\hline 0.3 & $\begin{array}{l}F_{(2,57.5)}=8.99 \\
p<0.001\end{array}$ & $\begin{array}{l}p=0.002 \\
\text { Neutral }>\text { cool }\end{array}$ & $\begin{array}{l}p<0.001 \\
\text { Neutral }>\text { warm }\end{array}$ & $p=0.452$ \\
\hline 1 & $\begin{array}{l}F_{(2,56.4)}=9.57 \\
p<0.001\end{array}$ & $\begin{array}{l}p<0.001 \\
\text { Neutral }>\text { cool }\end{array}$ & $\begin{array}{l}p=0.013 \\
\text { Neutral }>\text { warm }\end{array}$ & $p=0.065$ \\
\hline 3 & $\begin{array}{l}F_{(2,57.4)}=3.54 \\
p=0.035\end{array}$ & $\begin{array}{l}p=0.010 \\
\text { Neutral }>\text { cool }\end{array}$ & $p=0.160$ & $p=0.209$ \\
\hline 10 & $\begin{array}{l}F_{(2,58.1)}=4.20 \\
p=0.020\end{array}$ & $\begin{array}{l}p=0.008 \\
\text { Neutral }>\text { cool }\end{array}$ & $\begin{array}{l}p=0.030 \\
\text { Neutral }>\text { warm }\end{array}$ & $p=0.589$ \\
\hline 30 & $\begin{array}{l}F_{(2,54.4)}=1.21 \\
p=0.306\end{array}$ & $\mathrm{~N} / \mathrm{A}$ & $\mathrm{N} / \mathrm{A}$ & $\mathrm{N} / \mathrm{A}$ \\
\hline
\end{tabular}

At the velocities between 0.3 and $10 \mathrm{~cm} \mathrm{~s}^{-1}$, $\mathrm{CT}$ firing frequencies at the neutral temperature were significantly higher than the cool temperature, and also for the warm temperatures at $0.3,1$, and $10 \mathrm{~cm} \mathrm{~s}^{-1}$ stroking velocities. $\mathrm{N} / \mathrm{A}$ indicates that between-level tests were not applicable as the main effect was not significant.

and a significant main effect of stroking velocity $\left(F_{(4,313.0)}=\right.$ $14.82, p<0.001)$ and temperature $\left(F_{(2,313.7)}=14.37, p<0.001\right)$ were found, but no significant interaction of these. We conducted additional multilevel analyses at each stroking velocity to determine significant differences between the temperatures. There was a significant effect of temperature for all of the stroking velocities, apart from the fastest $\left(30 \mathrm{~cm} \mathrm{~s}^{-1}\right)$ : stroking at the neutral temperature produced significantly higher CT mean firing frequencies than stroking at cool or warm temperatures (apart from at 3 $\mathrm{cm} \mathrm{s}^{-1}$ where neutral was only significantly higher than cool; Table 1).

Myelinated mechanoreceptive afferents $(n=8$; locations shown in Fig. 1A) were also tested using the rotary mechanothermal stimuli, and data from four hair afferent units were compared directly with the CT responses. Regression analyses found striking differences compared with the CT responses: all of the 
individual hair units were better fit by positive quadratic regression models, rather than linear fits, and this was also true on a group level, per temperature $\left(R^{2}\right.$ for neutral, 0.92; cool, 0.89; warm, 0.85; all $p<0.001$; Fig. $2 C$ ). Multilevel statistics were conducted on the hair firing-frequency data: there was a significant main effect of stroking velocity $\left(F_{(4,155,1)}=492.96, p<\right.$ 0.001 ), where a substantial increase in firing frequency was found with faster velocities; however, no significant effects were found for the temperature of the stimulus or the interaction of stroking velocity and temperature. Additional recordings were made from two SA1 units, one SA2 unit, and one field unit (locations shown in Fig. 1A). These units showed considerable and significant increases in firing frequency with increasing velocity and, like the hair units, were best fit by positive quadratic models. The SA2, which was spontaneously active, showed an effect of temperature $\left(F_{(2,45)}=8.24, p=0.01\right)$, with significant decreases in firing frequency to warmth over all stroking velocities, compared with both cool and neutral temperatures $(p<0.05$; Chambers et al., 1972). There was little change in the firing frequency of the field unit to different temperatures, and both the SA1 units were only tested at one temperature before the recordings were lost.

In separate psychophysical experiments, participants rated the perceived pleasantness of mechano-thermal stroking on a visual analog scale. Participants perceived non-noxious cool and warm sensations, whereas in the neutral temperature condition, negligible temperature changes were felt. All of the individual participants' ratings were better fit by negative quadratic, rather than linear, regression models, and this was also true on a group level. For the neutral temperature, a significant inverted U-shaped, negative quadratic regression $\left(R^{2}=0.10, F_{(2,449)}=\right.$ 23.04, $p<0.001)$ best fit the pleasantness ratings to stroking velocity, where slower and faster velocities gave lower firing frequencies, compared with $3 \mathrm{~cm} \mathrm{~s}^{-1}$ (Fig. 2D). We found similar significant negative quadratic fits for the cool $\left(R^{2}=0.08\right.$, $\left.F_{(2,449)}=18.87, p<0.001\right)$ and warm $\left(R^{2}=0.13, F_{(2,449)}=\right.$ $34.23, p<0.001$ ) temperatures (Fig. 2D). Using a multilevel model, significant main effects were found for the stroking velocity $\left(F_{(4,1320)}=34.75, p<0.001\right)$, for the temperature $\left(F_{(2,1320)}=\right.$ $110.30, p<0.001)$, and for the interaction of velocity and temperature $\left(F_{(8,1320)}=5.66, p<0.001\right)$. Additional multilevel analyses at each stroking velocity found that there was a significant main effect of temperature from 0.3 to $10 \mathrm{~cm} \mathrm{~s}^{-1}$, where stroking at the neutral temperature was always perceived as significantly more pleasant than at cool or warm temperatures (all $p<0.05$ ).

Correlations were conducted between the CT and hair mean firing frequencies and the pleasantness ratings for corresponding temperatures. We found a significant correlation between the CT firing frequency and pleasantness ratings at the neutral temperature only ( $p=0.003, R^{2}=0.96$; Fig. $2 E$ ). No significant correlations were found for the cool or warm CT firing frequency and pleasantness ratings comparisons, or between the hair unit firing frequency and pleasantness ratings.

\section{Discussion}

CTs responded vigorously to slow stroking stimuli delivered at neutral, typical skin temperature, and CT firing frequencies correlated with hedonic ratings to the same mechano-thermal stimulus only at the neutral temperature. This adds strength to the affective touch hypothesis (Olausson et al., 2010), which predicts that CT afferents signal the affective elements of touch and are tuned to respond to direct skin-to-skin contact between individuals. When the moving tactile stimulus was set to warmer or cooler temperatures, compared with typical human skin temper- ature, the CT firing frequency decreased, as well as the pleasantness ratings.

CTs respond primarily to mechanical stimulation, although we show presently, using our novel bimodal stroking stimulation, that they are subject to thermo-modulatory effects. Previously, the effect of temperature on CT and CLTM afferents has only been studied using separately applied mechanical and thermal stimuli, where a response is sometimes seen to rapid cooling, with no response to warming (Iggo, 1960; Bessou et al., 1971; Hahn, 1971; Vallbo et al., 1999; Wiklund Fernström et al., 2003; Seal et al., 2009). In contrast, microneurographical recordings in humans have shown other types of afferents that are sensitive to cooling [C-cold (Campero et al., 1996, 2001, 2009; Campero and Bostock, 2010; Konietzny, 1984; Järvilehto and Hämäläinen, 1979); A $\delta$-cool (Campero et al., 2009)] and warming [C-warm (Konietzny and Hensel, 1977; Schmelz and Schmidt, 2010)]. The C-temperature afferents are often spontaneously active at typical skin temperature and respond well to rapid thermal changes, although they are unresponsive to mechanical stimulation. Additionally, C-polymodal nociceptors are activated by both cooling $\left(<20^{\circ} \mathrm{C}\right.$; Campero et al., 1996$)$ and heating $\left(>37^{\circ} \mathrm{C}\right.$; Schmidt et al., 1997).

At the cool and warm stimulus temperatures in the current work, there were additional sensory inputs from a range of temperature-sensitive afferents, which would inevitably influence the hedonic ratings. We chose to compare the neutral stroking temperature (comparable with skin-to-skin contact in social touch) with cool and warm stroking temperatures that were outside the boundary of typical skin temperatures $\left(21-37^{\circ} \mathrm{C}\right.$; Arens and Zhang, 2006) but were not considered painful. We show that stroking around typical skin temperature produced the highest CT firing frequencies, in contrast to the other temperature conditions, which resembled nonsocial touch as a result of the more intense thermal stimulation. The CT firing frequency likely has an optimal thermal range; therefore, investigations exploring responses over milder temperature changes may elucidate their role in social touch further.

At temperatures of $<20$ or $>44^{\circ} \mathrm{C}$, stimuli start to become unpleasant; however, participants can readily distinguish between the thermal, affective, and painful aspects (Greenspan et al., 2003). The perceived pleasantness of a thermal stimulus is dependent on core and skin temperature; cool stimuli are preferred during body warming and warm stimuli during body cooling, although temperature discrimination is independent of the affective quality (Cabanac, 1971; Marks and Gonzalez, 1974). In agreement with this, we found significantly lower pleasantness ratings for moving cool and warm stimuli compared with neutral stimuli. Our data show that when CT activity decreases (through nonoptimal stroking velocities and/or temperatures), the perceived pleasantness of the stimulus also decreases, providing support for the CT affective touch hypothesis. However, the correlation between CT firing and pleasantness was only found at the neutral temperature, demonstrating the effect of other factors than CT firing on pleasantness. These findings imply that the perception of pleasantness is multidimensional, constructed from all available sensory input, as well as being influenced by homeostatic state and top-down cognitive mechanisms.

The present data highlight differences between the physiological responses of CTs and myelinated hair afferents, with respect to their firing at different stroking velocities and temperatures. The hair afferents showed a substantial increase in their firing rate to faster stroking and showed no modulation to varying the stroking temperature. We found that the thicker terminal hairs in 
humans were innervated by myelinated afferents and were not physiologically related to CTs. Anatomically, CTs and animal CLTMs are associated with hairs: both afferent types are only found in hairy skin (Nordin, 1990; Vallbo et al., 1993, 1999; Wessberg et al., 2003; Liu et al., 2007; Löken et al., 2009; Li et al., 2011; Lou et al., 2013; Vrontou et al., 2013) and are located at a similar depth in the skin (Liu et al., 2007; Li et al., 2011; Lou et al., 2013). Despite similar thermal conduction distances from the skin surface, the hair afferents showed no significant effect for temperature (Hunt and McIntyre, 1960).

The significant relationship between the hedonic evaluation of the stroking stimuli at neutral temperature and the CT responses supports the role of CT afferents in affective, pleasant touch, particularly relating to skin-to-skin contact between individuals. These findings emphasize the importance of CTs in signaling tactile input in social interactions, such as in nurturing and romantic relationships. The evolutionary significance of an affective touch system would be to aid in parent-child and conspecific bonding, thus increase chances of survival through affiliative group behavior.

\section{References}

Arens E, Zhang H (2006) The skin's role in human thermoregulation and comfort. In: Thermal and moisture transport in fibrous materials ( $P a n N$, Gibson P, eds), pp 560-602. Cambridge, UK: Woodhead Publishing Ltd.

Bessou P, Burgess PR, Perl ER, Taylor CB (1971) Dynamic properties of mechanoreceptors with unmyelinated (C) fibers. J Neurophysiol 34:116131. Medline

Björnsdotter M, Löken L, Olausson H, Vallbo A, Wessberg J (2009) Somatotopic organization of gentle touch processing in the posterior insular cortex. J Neurosci 29:9314-9320. CrossRef Medline

Cabanac M (1971) Physiological role of pleasure. Science 173:1103-1107. CrossRef Medline

Campero M, Bostock H (2010) Unmyelinated afferents in human skin and their responsiveness to low temperature. Neurosci Lett 470:188-192. CrossRef Medline

Campero M, Serra J, Ochoa JL (1996) C-polymodal nociceptors activated by noxious low temperature in human skin. J Physiol 497:565-572. Medline

Campero M, Serra J, Bostock H, Ochoa JL (2001) Slowly conducting afferents activated by innocuous low temperature in human skin. J Physiol 535:855-865. CrossRef Medline

Campero M, Baumann TK, Bostock H, Ochoa JL (2009) Human cutaneous C fibres activated by cooling, heating and menthol. J Physiol 587:56335652. CrossRef Medline

Chambers MR, Andres KH, von Duering M, Iggo A (1972) The structure and function of the slowly adapting type II mechanoreceptor in hairy skin. Q J Exp Physiol 57:417-445. Medline

Greenspan JD, Roy EA, Caldwell PA, Farooq NS (2003) Thermosensory intensity and affect throughout the perceptible range. Somatosens Mot Res 20:19-26. CrossRef Medline

Hahn JF (1971) Thermal-mechanical stimulus interactions in lowthreshold C-fiber mechanoreceptors of cat. Exp Neurol 33:607-617. CrossRef Medline

Hunt CC, McIntyre AK (1960) An analysis of fibre diameter and receptor characteristics of myelinated cutaneous afferent fibres in cat. J Physiol 153:99-112. Medline

Iggo A (1960) Cutaneous mechanoreceptors with afferent C fibres. J Physiol 152:337-353. Medline

Iggo A, Kornhuber HH (1977) A quantitative study of C-mechanoreceptors in hairy skin of the cat. J Physiol 271:549-565. Medline

Järvilehto T, Hämäläinen H (1979) Touch and thermal sensations: psychophysical observations and unit activity in human skin nerves. In: Sensory functions of the skin of humans (Kenshalo DR, ed), pp 279-295. New York: Plenum.

Konietzny F (1984) Peripheral neural correlates of temperature sensations in man. Hum Neurobiol 3:21-32. Medline

Konietzny F, Hensel H (1977) The dynamic response of warm units in human skin nerves. Pflugers Arch 370:111-114. CrossRef Medline

Li L, Rutlin M, Abraira VE, Cassidy C, Kus L, Gong S, Jankowski MP, Luo W, Heintz N, Koerber HR, Woodbury CJ, Ginty DD (2011) The functional organization of cutaneous low-threshold mechanosensory neurons. Cell 147:1615-1627. CrossRef Medline

Liu Q, Vrontou S, Rice FL, Zylka MJ, Dong X, Anderson DJ (2007) Molecular genetic visualization of a rare subset of unmyelinated sensory neurons that may detect gentle touch. Nat Neurosci 10:946-948. CrossRef Medline

Löken LS, Wessberg J, Morrison I, McGlone F, Olausson H (2009) Coding of pleasant touch by unmyelinated afferents in humans. Nat Neurosci 12:547-548. CrossRef Medline

Lou S, Duan B, Vong L, Lowell BB, Ma Q (2013) Runxl controls terminal morphology and mechanosensitivity of VGLUT3-expressing C-mechanoreceptors. J Neurosci 33:870-882. CrossRef Medline

Marks LE, Gonzalez RR (1974) Skin temperature modifies the pleasantness of thermal stimuli. Nature 247:473-475. Medline

Morrison I, BjörnsdotterM, Olausson H (2011) Vicarious responses to social touch in posterior insular cortex are tuned to pleasant caressing speeds. J Neurosci 31:9554-9562. CrossRef Medline

Nordin M (1990) Low-threshold mechanoreceptive and nociceptive units with unmyelinated (C) fibers in the human supraorbital nerve. J Physiol 426:229-240. Medline

Olausson H, Lamarre Y, Backlund H, Morin C, Wallin BG, Starck G, Ekholm S, Strigo I, Worsley K, Vallbo AB, Bushnell MC (2002) Unmyelinated tactile afferents signal touch and project to insular cortex. Nat Neurosci 5:900-904. CrossRef Medline

Olausson H, Wessberg J, Morrison I, McGlone F, Vallbo A (2010) The neurophysiology of unmyelinated tactile afferents. Neurosci Biobehav Rev 34:185-191. CrossRef Medline

Schmelz M, Schmidt R (2010) Microneurographic single-unit recordings to assess receptive properties of afferent human C-fibers. Neurosci Lett 470: 158-161. CrossRef Medline

Schmidt R, Schmelz M, Ringkamp M, Handwerker HO, Torebjörk HE (1997) Innervation territories of mechanically activated C nociceptor units in human skin. J Neurophysiol 78:2641-2648. Medline

Seal RP, Wang X, Guan Y, Raja SN, Woodbury CJ, Basbaum AI, Edwards RH (2009) Injury-induced mechanical hypersensitivity requires C-low threshold mechanoreceptors. Nature 462:651-655. CrossRef Medline

Vallbo A, Olausson H, Wessberg J, Norrsell U (1993) A system of unmyelinated afferents for innocuous mechanoreception in the human skin. Brain Res 628:301-304. CrossRef Medline

Vallbo AB, Olausson H, Wessberg J, Kakuda N (1995) Receptive field characteristics of tactile units with myelinated afferents in hairy skin of human subjects. J Physiol 483:783-795. Medline

Vallbo AB, Olausson H, Wessberg J (1999) Unmyelinated afferents constitute a second system coding tactile stimuli of the human hairy skin. J Neurophysiol 81:2753-2763. Medline

Vallbo AB, Hagbarth KE, Wallin BG (2004) Microneurography: how the technique developed and its role in the investigation of the sympathetic nervous system. J Appl Physiol 96:1262-1269. CrossRef Medline

Vrontou S, Wong AM, Rau KK, Koerber HR, Anderson DJ (2013) Genetic identification of $\mathrm{C}$ fibers that detect massage-like stroking of hairy skin in vivo. Nature 493:669-673. CrossRef Medline

Wessberg J, Olausson H, FernströmKW, Vallbo AB (2003) Receptive field properties of unmyelinated tactile afferents in the human skin. J Neurophysiol 89:1567-1575. Medline

Wiklund Fernström K, Wessberg J, Vallbo A (2003) Temperature response of unmyelinated low-threshold mechanoreceptors (CT) in human hairy skin. Soc Neurosci Abstr 29:585.8.

Zotterman Y (1939) Touch, pain and tickling: an electro-physiological investigation on cutaneous sensory nerves. J Physiol 95:1-28. Medline 